\title{
An analysis of the Brazilian researchers on freshwater fish genetics and reproduction as coauthors in academic papers
}

\author{
Carlos Eduardo M. Viegas da Silva ${ }^{1,3}$, Elisabete Maria Macedo Viegas ${ }^{2}$ \\ ${ }^{1}$ Faculdade de Zootecnia e Engenharia de Alimentos (USP), Departamento de Engenharia de Biossistemas, \\ Pirassununga, SP, Brazil. \\ ${ }^{2}$ Faculdade de Zootecnia e Engenharia de Alimentos (USP), Departamento de Zootecnia, Pirassununga, SP.
}

\begin{abstract}
Science is a social activity in some senses: first, in any of its fields science is an accumulated body of knowledge inherited from generations of antecessors by its practitioners, the scientists. In second place, the results of the scientific findings are shared socially and finally, those results to be successfully achieved demands from the researchers a high grade of collaboration, through the formations of a social network. The collaboration between researchers may result in the publication of an academic article. This publication serves as an index of the existence of a social network of collaboration between researchers and may reveal how a specific field of knowledge has been established, who are the researchers that act as facilitators among colleagues as well as to give some clues about the direction the specific field may unfold. The objective of this work was apply techniques of Social Network Analysis on the community formed by the Brazilian researchers, that are granted a $\mathrm{CNPq}$ scholarship on research productivity, with an interest in genetics and reproduction of freshwater fishes. Their linkage in co-authoring research papers published by academic journals were examined. For the determination of this community and the academic articles, the existing data of researchers in the Platform Lattes of the $\mathrm{CNPq}$ database were extracted through the applicative ScriptLattes, which search for the works published in co-authorship. Later, on these data was applied a software dedicated to the Analysis of Social Networks, and graphs of social network and some of its metrics were obtained. The analysis found the Lattes CVs of 33 researchers who published 1156 articles in co-authorship in 502 different journals. As a result, the analysis shows that these researchers form an academic network with low density, and in twenty periodicals were published $25 \%$ of the articles produced in coauthorship by those researchers.
\end{abstract}

Keywords: Academic Network, coauthorship, fish reproduction scientific collaboration.

\section{Introduction}

The communities of scientists have attracted interest, as object of study, once the recognition that the deepening of scientific knowledge depends on the network structures formed by these communities
(Verspagen and Werner, 2004), at the same time when large databases with researcher's data became available over the internet. Through their work, their interaction, researchers form social networks by establishing strong ties between them, which are the links between advisors and advisees, or co-authorships in the publication of works resulting from the scientific research work (Granovetter, 1973).

The publication in co-authorship has been used as an indicator of cooperation between researchers (Lima, 2011), but it may be misleading because "not all collaboration results in an article and co-authorship does not always indicate collaboration" (Vanz and Stumpf, 2010). Having this observation in mind, this work starts from the assumption that academic researchers belong to a specialized field of knowledge establishing a social group whose foundation is, like any other social group, the division of labor and cooperation. Their individual members socialize themselves by means of the formation of network structures. In sociology, the theoretical foundations of this view can be found in the pioneering works of Georg Simmel (1858 - 1918).

In this study, the object of interest was the community of scientists formed by Brazilians researchers who were granted a scholarship called productivity in research by the National Research Council $(\mathrm{CNPq})$, having as object of interest the genetics and reproduction of freshwater fish. The starting point of this work is the assumption that when these researchers publish the results of their work in scientific articles written in co-authorship, they give materiality to the existence of a social network formed by researchers interested in genetics and reproduction of fish. This work assumes the hypothesis that, being so, on this network it is possible to apply some of the tools of Social Network Analysis, to understand some of its characteristics, measure its main features and draw conclusions about the use of scientific periodicals as well as evaluate the level of cooperation among researchers.

\section{Objectives}

To find the linkage between the CNPq holders of research productivity scholarships in freshwater fish genetics and reproduction by means of their works published as co-authors. To take this linkage as shaping a Social Network and analyze it using graphs to show and find its characteristics and metrics. 


\section{Materials and Methods}

The publicly accessible records existent in the Lattes Platform (Curriculum Lattes - CV Lattes) of the National Research Council (CNPq) database (Plataforma Lattes, 2017) were used in this analysis. The CNPq or the authors of this work are not liable for any flaws or inconsistencies in the data collected, since, according to the provisions of the $\mathrm{CNPq}$ website, the researchers are full responsible for the data quality fed into the Lattes Platform database. Initially, a search for the Lattes CVs was done on the $\mathrm{CNPq}$ website, in the Lattes Platform, filtering the results to identify the curricula of doctors who are $\mathrm{CNPq}$ productivity scholarship holders, at all levels this scholarship is granted. The search was done by subject, using the keyword "fish reproduction" and resulted in 302 CVs Lattes, which were examined one by one, manually, since many of the CVs selected by the website automatic search are incongruent with the goal of the inquiry, using the mentioned keyword. The manual selection of the initial sampling resulted in the selection of $33 \mathrm{CVs}$ Lattes of researchers whose work is related to genetics and/or reproduction of freshwater fish in Brazil. This selection returned their respective identifiers (id lattes), a code that allows the public access to the academic data of each researcher registered at this $\mathrm{CNPq}$ database.

In the next step a list composed by the id Lattes of the 33 selected researchers was processed by means of the software scriptLattes (Mena-Chalco and César, 2009), which performs the semiautomatic extraction of the Lattes CVs supplied by the list, analyzes them and searches the articles they published as coauthors, according to what each researcher has fed into the Platform Lattes database. Thus, it was possible to determine the articles published by the 33 researchers as coauthors, as well as to identify the periodicals used by them for the publishing, and the frequency each researcher published articles by periodical. On the collected data some tools and techniques of Social Network Analysis were applied, and metrics regarding coauthors were determined, as well as their representation in the form of social network graphs consisting of entities that are connected, or related to each other in some way; and is worth to note that the mathematical theory (Feofiloff et al., 2016) underlying this network analysis will not be addressed here. For the analysis of the academic collaboration network on genetics and fish reproduction, as well as to generate metrics and graphs of this network, it was used the Gephi software (Gephi Consortium, 2017), which is dedicated to the analysis of social networks. This list of names, processed using the ScriptLattes software, resulted in a data set that allowed the production of a graph with the Gephi applicative depicting the collaborative network among researchers as co-authors. The results obtained are shown below.

\section{Results}

The extraction of the information contained in the $33 \mathrm{CVs}$ Lattes of the researchers taken for this study resulted 1156 articles published in 502 different journals.
The manual selection of researchers, registered in the Lattes Platform, after filtered by the keyword "fish reproduction", nominated the following researchers:

List of CNPq's Researchers on Fish Genetics and Reprodction.

\author{
Alex Pires de Oliveira Nuñer \\ Diogo Teruo Hashimoto \\ Elizabeth Romagosa \\ Elizete Rizzo \\ Evoy Zaniboni Filho \\ Fábio Porto-Foresti \\ Fausto Foresti \\ Jayme Aparecido Povh \\ João Batista Kochenborger Fernandes \\ Leandro Cesar de Godoy \\ Luís André Nassr de Sampaio \\ Luis David Solis Murgas \\ Luis Fernando Fernandes Marins \\ Luiz Renato de França \\ Maria Ines Borella \\ Maria Iracilda da Cunha Sampaio \\ Nelson Ferreira Fontoura \\ Nilo Bazzoli \\ Renata Guimarães Moreira Whitton \\ Ricardo Pereira Ribeiro \\ Ricardo Vieira Rodrigues \\ Rilke Tadeu Fonseca de Freitas \\ Roberto Ferreira Artoni \\ Robie Allan Bombardelli \\ Robie Allan Bombardelli \\ Rodrigo Augusto Torres \\ Ronald Kennedy Luz \\ Ronaldo Oliveira Cavalli \\ Rosicleire Veríssimo Silveira \\ Sathyabama Chellappa \\ Sergio Ricardo Batlouni \\ Silvio Ricardo Maurano Peixoto \\ Tarcízio Antônio Rêgo de Paula \\ Wilson Francisco Britto Wasielesky Junior
}

The graph of Figure 1 is a representation of how the Brazilian researchers, who are granted a productivity research scholarship by $\mathrm{CNPq}$, in the field of genetics and reproduction of freshwater fish, collaborate with each other through the coauthoring of papers in scientific journals. In this representation, each point is a researcher and each line represents a coauthoring interaction. The size of the letter type used in the researcher's name is proportional to the amount of researcher's co-author role with the other colleagues (their degree) and the thickness of the lines linking one researcher to another is proportional to the quantity of works published in co-authorship between these researchers. Due to their degree of collaboration, measured by the number of works published with others, each researcher has a different impact on the set of collaborations of the social network of coauthors, which is measured by their collaboration rank (Page et al., 1999). Below is a table (Tab. 1), produced by the applicative ScriptLattes, which reports this metric for each researcher involved. 


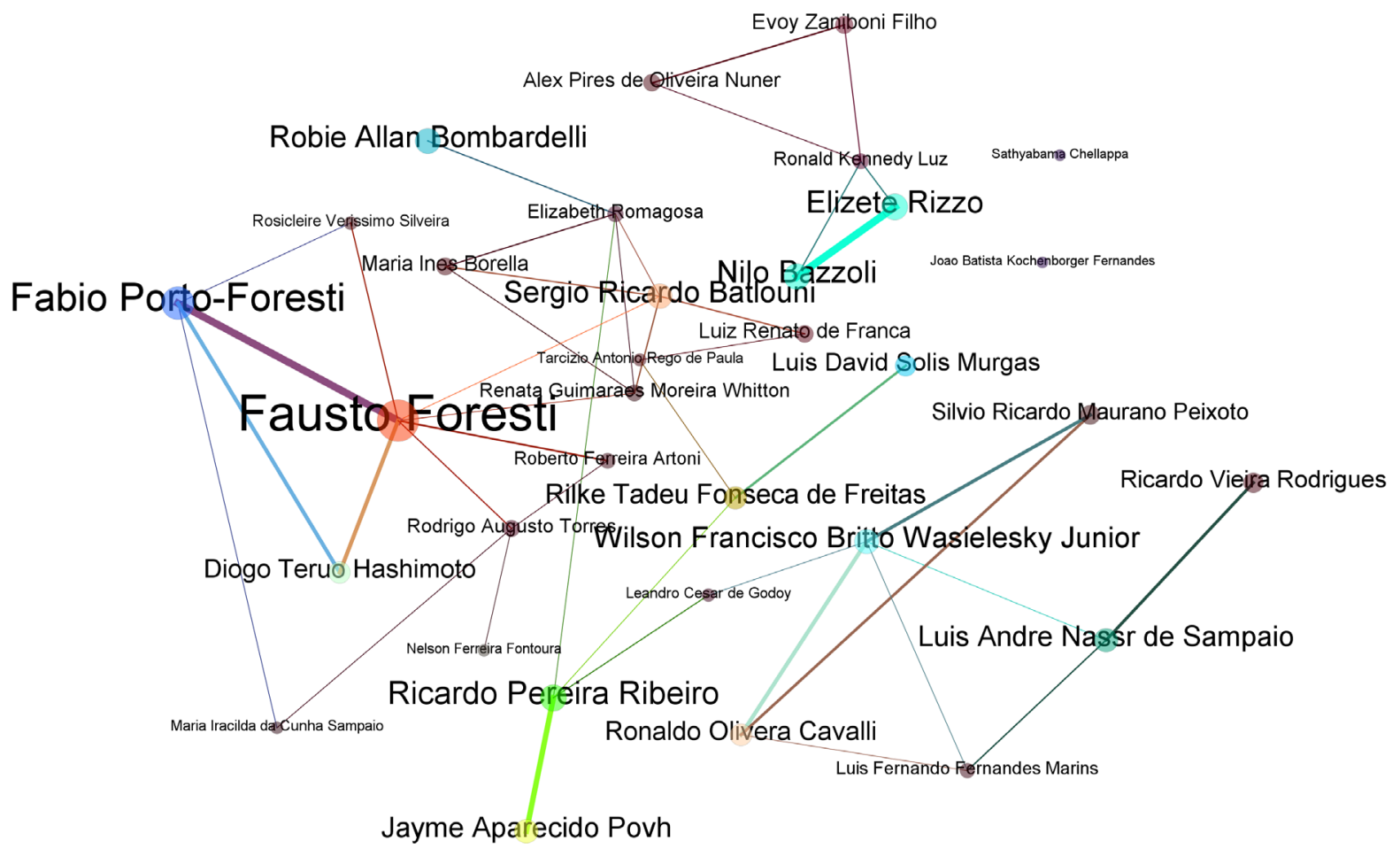

Figure 1. Graph of the collaboration network in publishing academic papers among co-authors researchers.

Table 1. Researchers classified in decreasing order by collaboration rank.

\begin{tabular}{ll}
\hline Names & Collaboration Rank \\
\hline Fausto Foresti & 3.0 \\
Fábio Porto-Foresti & 2.16 \\
Ricardo Pereira Ribeiro & 1.56 \\
Nilo Bazzoli & 1.51 \\
Elizete Rizzo & 1.51 \\
Robie Allan Bombardelli & 1.45 \\
Robie Allan Bombardelli & 1.45 \\
Sergio Ricardo Batlouni & 1.41 \\
Wilson Francisco Britto Wasielesky Junior & 1.37 \\
Jayme Aparecido Povh & 1.31 \\
Luís André Nassr de Sampaio & 1.3 \\
Rilke Tadeu Fonseca de Freitas & 1.19 \\
Ronaldo Olivera Cavalli & 1.13 \\
Diogo Teruo Hashimoto & 1.11 \\
Luis David Solis Murgas & 1.05 \\
Ricardo Vieira Rodrigues & 0.95 \\
Silvio Ricardo Maurano Peixoto & 0.91 \\
Evoy Zaniboni Filho & 0.74 \\
Maria Ines Borella & 0.72 \\
Luiz Renato de França & 0.71 \\
Alex Pires de Oliveira Nuñer & 0.69 \\
Rodrigo Augusto Torres & 0.63 \\
Renata Guimarães Moreira Whitton & 0.63 \\
Elizabeth Romagosa & 0.58 \\
Ronald Kennedy Luz & 0.55 \\
Roberto Ferreira Artoni & 0.53 \\
Luis Fernando Fernandes Marins & 0.48 \\
Rosicleire Veríssimo Silveira & 0.33 \\
Leandro Cesar de Godoy & 0.29 \\
Tarcízio Antônio Rêgo de Paula & 0.28 \\
Maria Iracilda da Cunha Sampaio & 0.25 \\
Nelson Ferreira Fontoura & 0.22 \\
Sathyabama Chellappa & 0.15 \\
João Batista Kochenborger Fernandes & 0.15 \\
\hline
\end{tabular}


This classification of the researchers allowed to select the top ten Brazilian researchers with the highest degree of collaboration as coauthors, in the publication of works related to genetics and reproduction of fish, among the other 33 listed and to determine the academic journals where those publications were made. Processing the data with the Gephi platform, it was possible to obtain the graph shown below (Fig. 2).

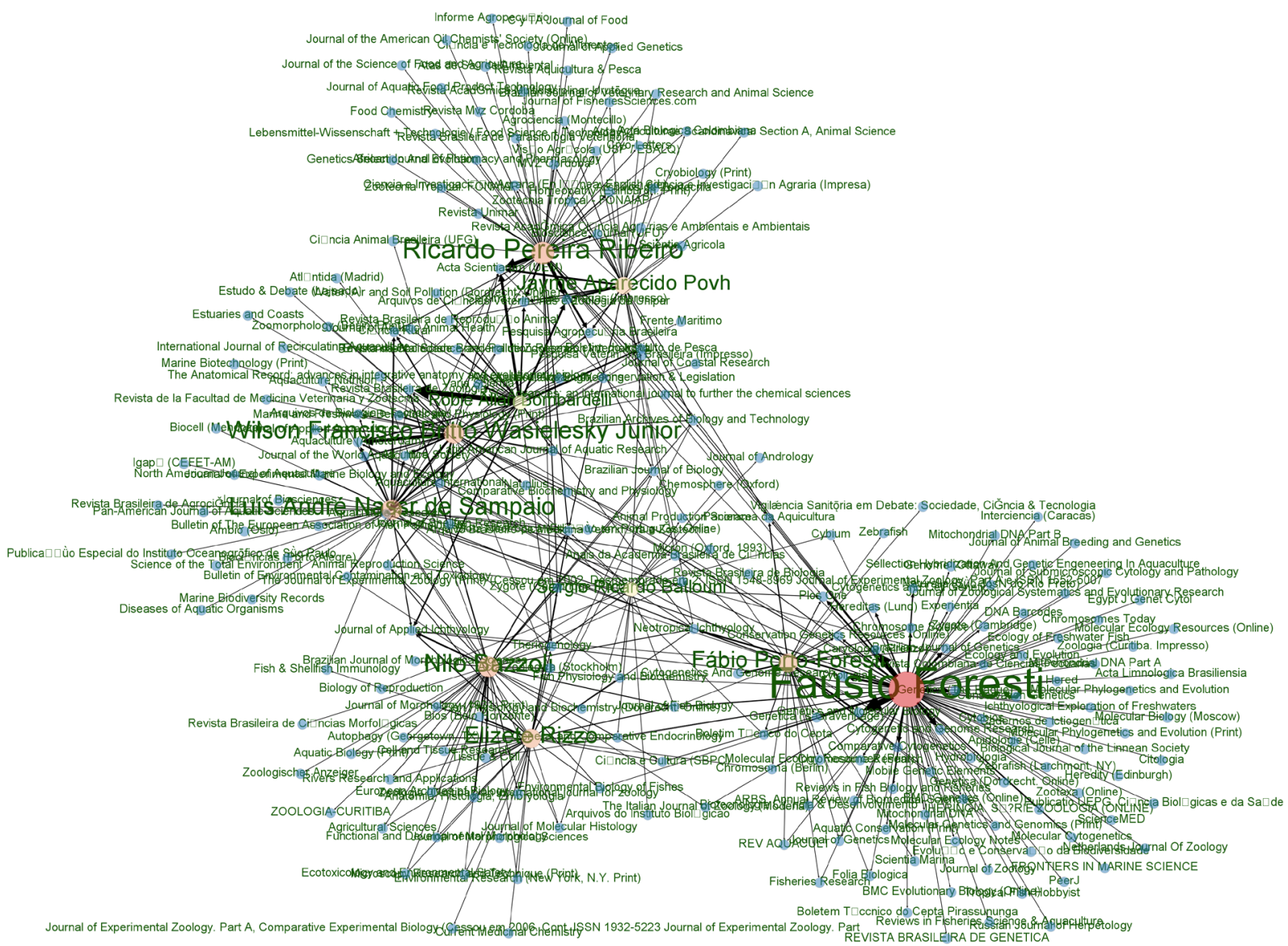

Figure 2. Graph of scientific network formed by journals and most collaborative authors.

In this graph the green lines represent a link between a researcher and a journal, and the size of the font type used in the researcher's name is proportional to the number of publications made by that researcher. The green dots represent different journals and the line thickness is proportional to the number of articles the researcher published in that periodical. The next graph (Fig. 3) represents the same relationship in an inverted way and describes which journals were the ones that received the largest amount of article publications by the ten researchers with the greatest degree of collaboration among them. The font type size used in the names of journals is proportional to the number of articles published in each of them and the thickness of the lines is proportional to the number of articles published per researcher.

The Table 2 shown below lists forty journals used by the ten researchers with the highest degree of collaboration as coauthors in genetics and reproduction of freshwater fish, for publishing theirs works. These journals belong to the universe of 502 journals listed. The entrance degree (indegree) measures the number of articles published by these researchers in the periodical in question and the Page Rank means is an index to measure the number of times the periodical was used, relative to all other periodicals.
Using the Gephi software, another analysis was applied on the collaboration network formed by the group of 33 researchers, this time with the purpose of analyzing the general characteristics of this network (Scott, 2011). The results are shown in Figure 4 and in Table 3. Figure 4 represents the degree of centrality of intermediation between the members of the network (betweenness centrality), which is a metric that shows the extent into a member of a social network is connected to the other components of the network, acting as a "bridge" between them.

The data set, collected from the Lattes Platform, to locate the co-authorship in academic articles produced by researchers granted by $\mathrm{CNPq}$ with a scholarship, through the keyword "fish reproduction", brought some biases using the search tools available on the $\mathrm{CNPq}$ website. One bias, the most serious of the data extraction, was to list many names of researchers who do not work with animal reproduction at all, or who work with reproduction of other animals but not with the reproduction of fish properly. Another bias resulted in the collection of names of researchers who work with genetics of fish, but not properly with their reproduction. These biases had to be adjusted manually and, therefore, it is more convenient to analyze the results obtained in terms of coauthors in genetics and fish reproduction. 


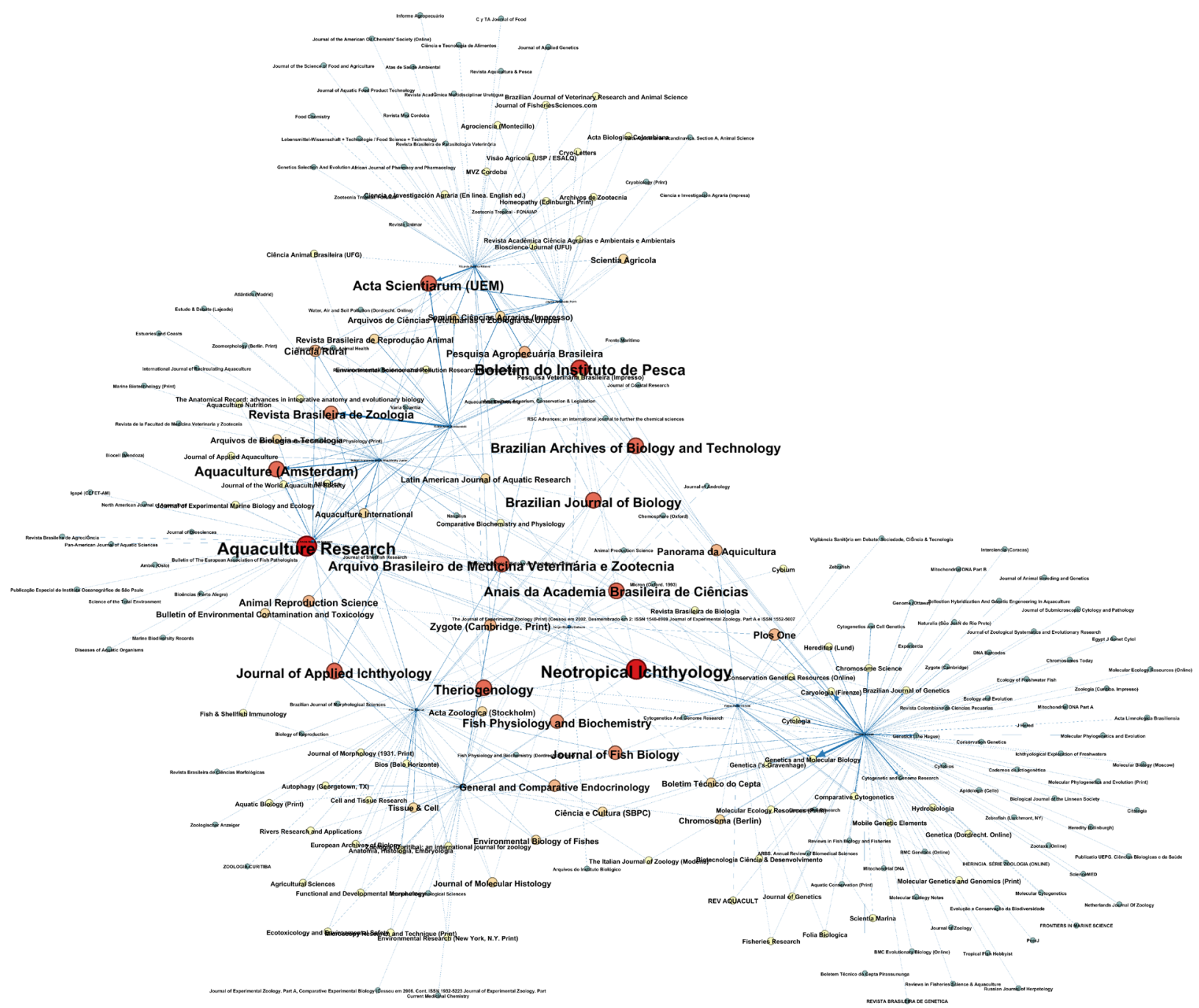

Figure 3. Graph of scientific network formed by authors and the most used journals.

The co-authored production of scholarly articles in the subject analyzed has an expressive concentration on just a single researcher, who participate in about $30 \%$ of the total published articles, which perhaps can be explained for this researcher being a senior one with extensive academic life and his $\mathrm{CV}$ Lattes reports the bibliographic production throughout a whole academic career. On the other hand, it is also significant the dispersion in terms of the number of journals used by researchers for the publication of their works, totaling 502 journals with the most diverse characteristics. One way to evaluate this dispersion is to check the number of articles published per periodical. Taking in decreasing order the first three journals most searched after by researchers, the figure is 24 articles for the most wanted, 21 for the second place and 19 articles for the third one. However, the last 311 less-wanted journals received only one article for publication, meaning that in twenty journals there was a concentration of $25 \%$ of the total articles published by these researchers. It is also worth noting that among the forty most wanted journals a presence of Brazilian journals alongside with non-Brazilian journals, which may suggest that several Brazilian journals are vehicles that have a good reputation among researchers in the field.
Table 3 (above) shows the positioning metrics of the researchers, taken the general set of the collaboration network, that is, this measure considers the importance of each researcher in the collaboration network as a whole. From this table it is possible to notice that although the third author (in the order) has a bibliographic production more than four times superior to the first one, the first in the rank has a greater degree of intermediation between the coauthors. The PageRank index roughly measures the number of times a page (e.g.: the number of times a website page is visited) is accessed; and for this analysis, this index is correlated to the bibliographic production (the quantity of articles published), which does not capture the impact of the researcher in terms of his/her academic collaboration for the whole network of researchers. In order to examine this feature, it is necessary to determine its centrality of intermediation, which, in the case of the network examined, represents the position of one researcher as an intermediary among other researchers, that is, even if researcher A does not have an article published as coauthor with researcher $\mathrm{C}$, it may exist author $\mathrm{B}$ who is a co-author with $\mathrm{A}$ and $\mathrm{C}$, acting as a bridge between them. This is an important metric for locating 
agents who play a key role in any social network and in the case examined, shows the network of co-authors with a different dimension than the rough number of paired collaborations between single members. This measurement is illustrated by the graph of Figure 4 , produced from the data of Table 3, which highlights other researchers than those represented in the graph of Figure 3.

Table 2. List of forty journals used by the ten researchers with the highest degree of collaboration as coauthors in genetics and reproduction of freshwater fish.

\begin{tabular}{|c|c|c|c|c|}
\hline \# & Journal & indegree & degree & pageranks \\
\hline 1 & Neotropical Ichthyology & 24 & 24 & 0.003373 \\
\hline 2 & Aquaculture Research & 21 & 21 & 0.003267 \\
\hline 3 & Arquivo Brasileiro de Medicina Veterinária e Zootecnia & 19 & 19 & 0.003016 \\
\hline 4 & Journal of Applied Ichthyology & 19 & 19 & 0.002876 \\
\hline 5 & Boletim do Instituto de Pesca & 18 & 18 & 0.003586 \\
\hline 6 & Revista Brasileira de Zoologia & 17 & 17 & 0.003597 \\
\hline 7 & Acta Scientiarum (UEM) & 16 & 16 & 0.003903 \\
\hline 8 & Aquaculture (Amsterdam) & 16 & 16 & 0.003382 \\
\hline 9 & Brazilian Archives of Biology and Technology & 15 & 15 & 0.002575 \\
\hline 10 & Theriogenology & 15 & 15 & 0.002351 \\
\hline 11 & Journal of Fish Biology & 14 & 14 & 0.002454 \\
\hline 12 & Brazilian Journal of Biology & 14 & 14 & 0.002265 \\
\hline 13 & Fish Physiology and Biochemistry & 13 & 13 & 0.002437 \\
\hline 14 & Anais da Academia Brasileira de Ciências & 13 & 13 & 0.002216 \\
\hline 15 & Ciência Rural & 13 & 13 & 0.002524 \\
\hline 16 & Pesquisa Agropecuária Brasileira & 12 & 12 & 0.002573 \\
\hline 17 & Plos One & 12 & 12 & 0.00236 \\
\hline 18 & Animal Reproduction Science & 12 & 12 & 0.002352 \\
\hline 19 & Revista Brasileira de Reprodução Animal & 11 & 11 & 0.00236 \\
\hline 20 & Journal of the World Aquaculture Society & 10 & 10 & 0.002301 \\
\hline 21 & Boletim Técnico do Cepta & 9 & 9 & 0.002153 \\
\hline 22 & Aquaculture International & 9 & 9 & 0.002619 \\
\hline 23 & Genetics and Molecular Biology & 8 & 8 & 0.002776 \\
\hline 24 & Tissue \& Cell & 8 & 8 & 0.002185 \\
\hline 25 & Zygote (Cambridge. Print) & 8 & 8 & 0.00245 \\
\hline 26 & General and Comparative Endocrinology & 8 & 8 & 0.002244 \\
\hline 27 & Hydrobiologia & 7 & 7 & 0.001976 \\
\hline 28 & Revista Brasileira de Biologia & 7 & 7 & 0.00214 \\
\hline 29 & Scientia Agricola & 7 & 7 & 0.001916 \\
\hline 30 & Ciência Animal Brasileira (UFG) & 7 & 7 & 0.001961 \\
\hline 31 & Atlântica & 7 & 7 & 0.002331 \\
\hline 32 & Conservation Genetics Resources (Online) & 6 & 6 & 0.002137 \\
\hline 33 & Environmental Biology of Fishes & 6 & 6 & 0.002022 \\
\hline 34 & Comparative Biochemistry and Physiology & 6 & 6 & 0.002082 \\
\hline 35 & Caryologia (Firenze) & 5 & 5 & 0.002138 \\
\hline 36 & Comparative Cytogenetics & 5 & 5 & 0.001976 \\
\hline 37 & Journal of Genetics & 5 & 5 & 0.001863 \\
\hline 38 & Panorama da Aquicultura & 5 & 5 & 0.002064 \\
\hline 39 & Zebrafish (Larchmont, NY) & 5 & 5 & 0.001945 \\
\hline 40 & Ciência e Cultura (SBPC) & 5 & 5 & 0.001918 \\
\hline
\end{tabular}

Finally, the collaborative academic network examined has a density equal to $8.1 \%$ as measured by Gephi software. To understand this metric, it is enough to know that a network in which all its components are linked to each other, has a density equal to $100 \%$ and, therefore, the network under analysis has a low density, meaning that the collaboration between these researchers in the publication of academic articles is less than their potential for collaboration. The meaning of this metric is reinforced by two other measurements: the diameter of this network is 9 and its average length is 3.8 (measurements obtained by the Gephi ). The diameter of a network is the maximum distance that separates two of its components, measured by the number of network members between them. As a network (social or otherwise) may have a diameter of hundreds (or more) of components, the network in question is not large. The average length is the metric that measures the average minimum distance for one member to reach another member (necessarily, it is smaller than its diameter) and the figure reinforces the small size of the network and emphasizes its low density. 


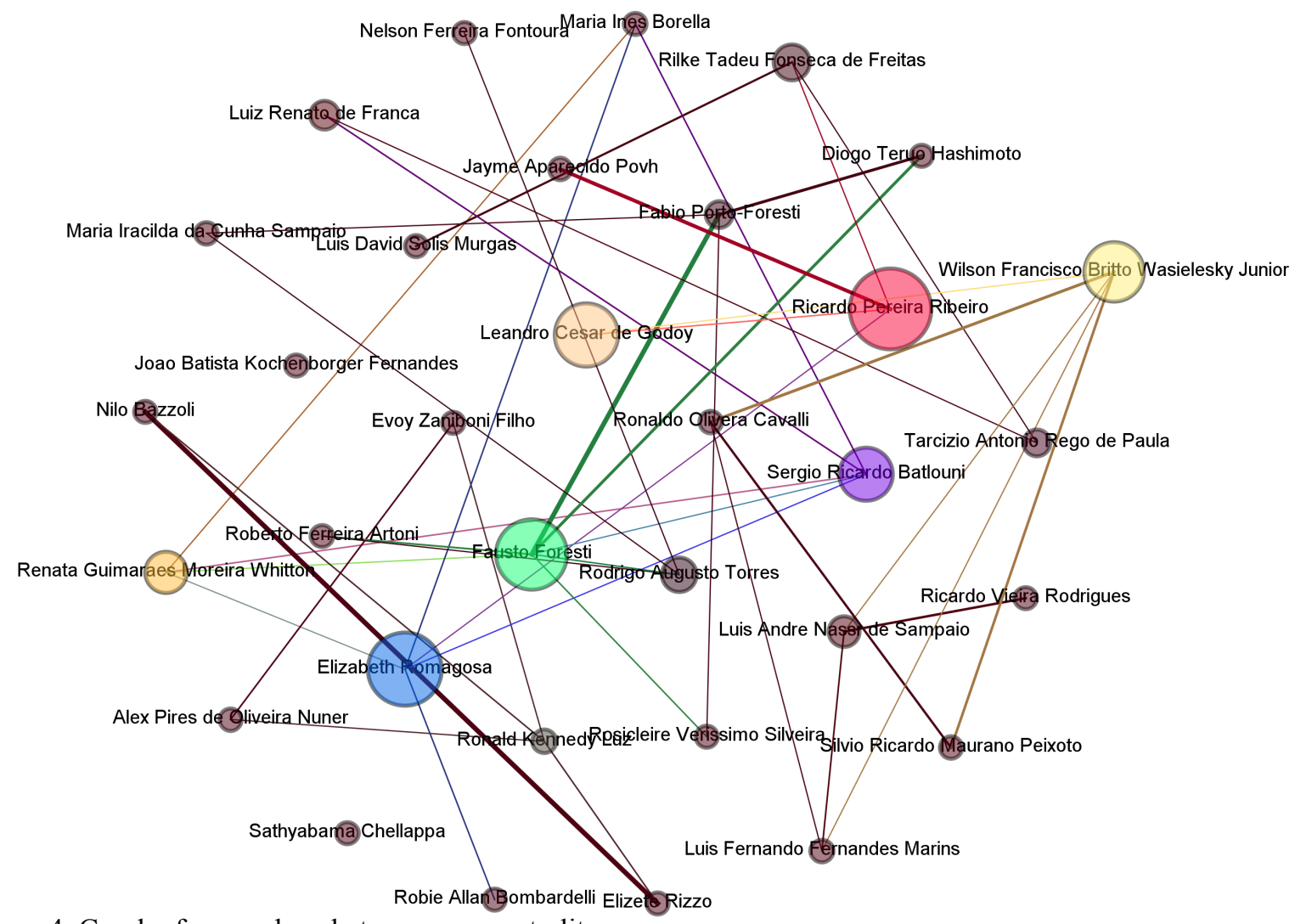

Figure 4. Graph of researchers betweenness centrality.

Table 3. Researchers ordered by the centrality of intermediation (betweenness centrality).

\begin{tabular}{llllll}
\hline Id & Label & $\begin{array}{l}\text { Bibliografic } \\
\text { Production }\end{array}$ & Articles in Journals & $\begin{array}{l}\text { Betweeness } \\
\text { Centrality }\end{array}$ & Page Ranks \\
\hline 13 & Fausto Foresti & 1171 & 334 & 271169 & 96597 \\
16 & Ricardo Pereira Ribeiro & 268 & 153 & 329973 & 51543 \\
8 & Sergio Ricardo Batlouni & 105 & 30 & 173723 & 50348 \\
2 & Elizete Rizzo & 386 & 86 & 0 & 48594 \\
3 & Nilo Bazzoli & 411 & 107 & 0 & 48594 \\
27 & Diogo Teruo Hashimoto & 181 & 38 & 0 & 46829 \\
24 & Wilson Francisco Britto Wasielesky Junior & 623 & 146 & 208669 & 43747 \\
21 & Jayme Aparecido Povh & 215 & 76 & 0 & 43097 \\
18 & Luis Andre Nassr de Sampaio & 381 & 93 & 48387 & 39722 \\
22 & Ronaldo Olivera Cavalli & 326 & 78 & 1008 & 37997 \\
15 & Rilke Tadeu Fonseca de Freitas & 422 & 213 & 77621 & 37968 \\
5 & Elizabeth Romagosa & 173 & 83 & 288642 & 34755 \\
25 & Silvio Ricardo Maurano Peixoto & 270 & 69 & 0 & 32721 \\
30 & Maria Ines Borella & 108 & 37 & 0 & 30989 \\
31 & Ricardo Vieira Rodrigues & 126 & 26 & 0 & 29219 \\
1 & Renata Guimaraes Moreira Whitton & 214 & 56 & 107527 & 23367 \\
23 & Luiz Renato de Franca & 338 & 129 & 36962 & 22212 \\
4 & Evoy Zaniboni Filho & 401 & 91 & 0 & 21657 \\
6 & Ronald Kennedy Luz & 413 & 74 & 8065 & 20653 \\
17 & Alex Pires de Oliveira Nuner & 197 & 34 & 0 & 20246 \\
26 & Robie Allan Bombardelli & 355 & 70 & 0 & 15344 \\
29 & Luis Fernando Fernandes Marins & 202 & 80 & 2016 & 14233 \\
10 & Roberto Ferreira Artoni & 243 & 134 & 0 & 14154 \\
20 & Rosicleire Verissimo Silveira & 216 & 22 & 0 & 9175 \\
28 & Leandro Cesar de Godoy & 106 & 24 & 229839 & 9093 \\
14 & Tarcizio Antonio Rego de Paula & 204 & 90 & 25874 & 8945 \\
12 & Maria Iracilda da Cunha Sampaio & 317 & 159 & 2016 & 7441 \\
9 & Fabio Porto-Foresti & 423 & 79 & 24194 & 7246 \\
11 & Nelson Ferreira Fontoura & 99 & 58 & 0 & 6757 \\
0 & Joao Batista Kochenborger Fernandes & 193 & 83 & 0 & 4792 \\
19 & Sathyabama Chellappa & 447 & 130 & 0 & 4992 \\
7 & Luis David Solis Murgas & 481 & 135 & 0 & 3347 \\
33 & Rodrigo Augusto Torres & 121 & 44 & 69556 & 1849 \\
\hline & & & & & \\
& & & & & 0 \\
\end{tabular}


In conclusions, the analysis of the social network, formed by the Brazilian researchers in genetics and fish reproduction, granted with a scholarship in research productivity by $\mathrm{CNPq}$, through their collaboration in coauthoring the publication of academic papers, reveals that there are some opportunities for improvement in terms of their collaboration. Initially, it is possible to say that the low density of this network $(8.1 \%)$ suggests that it is possible to increase the collaboration and measure it through the works published by coauthors. Although the authors' survey found 33 names, there is a strong concentration of authorship in a few names. An increase in the academic partnerships would lead to an increase in the density of the network, meaning a more cohesive social group, and perhaps a more integrated scientific community. On the other hand, there is a significant dispersion in the application of papers to be published by the academic journals; as a result, three hundred different journals have received only one application for publication. Among those most in demand, there are some Brazilian journals, which suggests that an increase in the applications of academic papers in these journals could lead to an improvement in their international ranking and to strengthen the collaboration between authors.

\section{Acknowledgements}

The corresponding author has received from CNPq a support grant, process 454647 / 2014 - 0, which provided the resources to make this work feasible.

Authors would to thank Prof. Dr. Jesus MenaChalco, UFABC Federal University, Brazil, for his guidance on the use of ScriptLattes software and suggestions about Social Network Analysis.

\section{References}

Feofiloff P, Kohayakawa Y, Wakabayashi Y. 2016. Uma Teoria Sucinta à Teoria dos Grafos. Available in http://www.ime.usp.br/ pff/teoriadosgrafos. Accessed on 13-jan-2016.

Gephi Consortium. 2017. Computer Program. Available from: https://www. gephi.org. Accessed on 08-11-2017.

Granovetter M. 1973. The Strength of Weak Ties. American Journal of Sociology. 78(6):1360-1380.

Lima MY. 2011. Coautoria na produção científica do PPGGeo/UFRGS: uma análise de redes sociais. Ciência da Informação, 40(1):38-51.

Mena-Chalco JP and Cesar-Jr RM. 2009. scriptLattes: An open-source knowledge extraction system from the Lattes platform. Journal of the Brazilian Computer Society, 15(4):31-39

Page L, Brin S, Motwani R, Winograd T. 1999. The PageRank Citation Ranking: Bringing Order to the Web. Stanford, CA: Stanford InfoLab. 17 pp. (Technical Report, 1999-66).

Plataforma Lattes [database on internet]. 2017. Available on: www.lattes.cnpq.br. Accessed on: November, 8,2017.

Scott J. 2011. Social Network Analysis. SAGE Publications Ltd., London.

Vanz SAS, Stumpf IRC. 2010. Colaboração científica: revisão teórico-conceitual. Perspectivas em Ciência da Informação, 15(2):42-55.

Verspagen B, Werker C. 2004. Keith Pavitt and the Invisible College of the Economics of Technology and Innovation. Research Policy, 33:1419-1431 